ISSN 1112-9867

Available online at

http://www.jfas.info

\title{
CHEMICAL COMPOSITION AND ANTIOXIDANT ACTIVITY OF APIS MELLIFERA BEE POLLEN FROM NORTHWEST ALGERIA
}

\author{
A. Rebiai* and T.Lanez
}

University of El Oued, VTRS Laboratory, P.O. Box 789, 39000, El Oued, Algeria

Received: 08 November 2012 / Accepted: 23 December 2012 / Published online: 31 December 2012

\begin{abstract}
The aim of this study was to assess the nutritional composition and antioxidant activity of bee pollen produced in the North western region of Algeria. The content of total phenolic compounds, flavonoids, and antioxidant activity using the molybdate ion reduction method were determined. The mean contents of phenolic compounds and total flavonoids were 30.46 $\pm 8.22 \mathrm{mg}$ of GAE. $\mathrm{g}^{-1}$ pollen and $8.92 \pm 5.5 \mathrm{mg}$ of $\mathrm{RE} . \mathrm{g}^{-1}$ pollen, respectively. High antioxidant activities were found for the molybdate ion reduction method, with values that ranged from 71.95 to $101.5 \mathrm{~g}$ of GAE. $\mathrm{g}^{-1}$ pollen. The bee pollen of Boufarik showed high antioxidant activity probably due to the high content of phenolic compounds present in pollen.
\end{abstract} Key words: Bee pollen; Phenolic compounds; Flavonoids; Antioxidant activity; Molybdate.

\section{INTRODUCTION}

Bee pollen has been used for many years in both traditional medicine and supplementary nutrition, as well as in alternative diets, mainly due to its nutritional properties and health benefits.

Bee pollen is the result of the agglutination of flower pollens; it is made by worker honey bees with nectar and salivary substances and stored at the hive entrance [1]. The collection of bee pollen is a relatively recent development, dependent primarily on the basic concept of scraping pollen off of the bees' legs as they enter the hive.

Author Correspondence, e-mail: k_rebiai@yahoo.fr

ICID: 1025902 
When analyzing and studying the nutritional and therapeutic properties of bee pollen, modern science has made it possible to specify its valuable antimicrobial [2], antifungal [3], antioxidant [4], anti-radiation [5], hepatoprotective [6], chemopreventive [7], anticancer [8] and antiinflammatory activities [9].

The major components of bee pollen are carbohydrates, crude fibers, proteins and lipids at proportions ranging between 13 to $55 \%, 0.3$ to $20 \%, 10$ to $40 \%, 1$ to $10 \%$, respectively. Other minor components such as minerals and trace elements, vitamins and carotenoids, phenolic compounds, flavonoids, sterols and terpenes can also be found [10]. In fact, BP is referred to as the "only perfectly complete food", as it contains all the essential amino acids needed for the human organism. However, the composition of BP depends strongly on the plant source and geographic origin, together with other factors such as climatic conditions, soil type, and beekeeper activities.

During the last decade, interest in the study of phenolic compounds has increased greatly, mainly due to the antioxidant capacity of these substances in scavenging free radicals that are harmful to human health [11]. The antioxidant activity of phenolic compounds depends on the chemical structure and can be determined by the action of the molecule as reducing agents (speed of free radical inactivation, reactivity with other antioxidants and metal chelating potential). In vitro trials have demonstrated that some flavonoids have greater antioxidant activity than vitamins E and C [12]. Epidemiologic studies have also demonstrated positive correlation between the increase in phenolic compound consumption with antioxidant action [13] and reduction of the risk of cardiovascular diseases and certain types of cancer [14].

The biological properties of phenolic compounds are related to the activity that each phenol exercises in a certain medium, and the chemical structure of flavonoids favors antioxidant action. The high capacity of the phenolic constituents to neutralize the species reactive to oxygen are strongly associated with their structure, such as conjugated double bonds and number of hydroxyls in the aromatic ring of flavonoids and cinnamic acid derivatives [15]. The radical DPPH is widely used to test the free radical scavenger capacity in apicultural products such as, pollen [16], propolis [17] and honey [18]. The antioxidant activity using the stable free radical DPPH is based on the transfer of electrons from an antioxidant compound to a free radical, DPPH which, when it is reduced, loses its purple coloring. Thus, only the reducing power of the antioxidant is assessed, which becomes oxidized when it donates an electron, and for this reason does not detect pro-oxidant substances [19]. 
The aim of this study was to assess the nutritional composition and DPPH scavenging activity of the bee pollen produced in the North western region of Algeria, by bees of the A. mellifera species.

\section{MATERIAL AND METHODS}

\subsection{Chemicals}

3,4,5-Trihydroxybenzoic acid (gallic acid; GA) (99\%), butylated hydroxyanisole (BHA) (96\%), ascorbic acid (AA) (99\%), were procured from Alfa Aesar (Etats-Unis). Sodium phosphate (extra pure), sulfuric acid (98\%), aluminum chloride and sodium carbonate were purchased from Prolabo (Etats-Unis). The Folin-Ciocalteu reagent (FCR), ammonium molybdate, methanol and hexane were obtained from BIOCHEM chemopharma Co (France). High purity water was used in all experiments. All other reagents used were of analytical grade.

\subsection{Instrumentation and software.}

Spectrophotometric measurements were performed on an UV-1700 Schimadzu Spectrophotometer (double-beam) equipped with $1 \mathrm{~cm}$ quartz cuvettes.

\subsection{Bee pollen samples}

Five dehydrated bee pollen samples were collected by beekeepers from different locations in Northwest Algeria (Table 01), during the period from 2010 to 2011. After collection, the bee pollens were sent to the laboratory and each sample was separately crushed in commercial blender, homogenized and stored in freezer for later analysis. 
Table 1. Algerian bee pollen samples used in this study on the basis of date of harvest, geographical origin

\begin{tabular}{cccccc}
\hline $\begin{array}{c}\text { Sample } \\
\text { code }\end{array}$ & $\begin{array}{c}\text { Type of bee } \\
\text { pollen }\end{array}$ & Predominant plant & $\begin{array}{c}\text { Date of } \\
\text { harvest }\end{array}$ & $\begin{array}{c}\text { Place of } \\
\text { production }\end{array}$ & $\begin{array}{c}\text { Geographical } \\
\text { origin }\end{array}$ \\
\hline P01 & Monoflora & Wild Carrot & 2010 & Boufarik, Blida & Mountain \\
P02 & Monoflora & Rosemary & 2010 & Boufarik, Blida & Mountain \\
P03 & Monoflora & Eucalyptus & 2011 & Boudouaou, & Mountain \\
P04 & Heteroflora & $/$ & 2010 & Boumerdès & Tipaza \\
P05 & Heteroflora & $/$ & 2010 & Birtouta, Algiers & Field (Mitidja) \\
\hline
\end{tabular}

\section{METHODS}

\subsection{Extraction of bee pollen compounds}

Extraction of pollen contents was achieved using methanol as a solvent. A $5 \mathrm{~g}$ sample of pollen was extracted for $2 \mathrm{~h}$ in a Soxhlet apparatus with $175 \mathrm{ml}$ methanol at $70^{\circ} \mathrm{C}$. The crude extracts were pooled and concentrated in a rotary evaporator and kept in small $(20 \mathrm{ml})$ sterile dark bottles under refrigerated conditions until use.

\subsection{Determination of Total polyphenolics Content}

Total polyphenolic content (TPC) was determined using Folin-Ciocalteu reagents according to the method of Kumazawa et al [17], briefly described as $0.5 \mathrm{ml}$ of Folin and Ciocalteu's phenol reagent was mixed with $100 \mu \mathrm{l}$ extract solution. After $3 \mathrm{~min}, 2 \mathrm{ml}$ of $20 \%$ aqueous sodium carbonate solution was added to the mixture. The reaction was kept in the dark for 30 min, after which the absorbance was read at $\lambda=760 \mathrm{~nm}$.

Gallic acid was used as the standard to produce the calibration curve $(0.03-0.3 \mathrm{mg} / \mathrm{ml})$. The mean of three readings was used and the total polyphenolic content expressed in $\mathrm{mg}$ of gallic acid equivalents (GAEs) (mg/100g).

\subsection{Determination of Total Flavonoids Content}

Total flavonoid contents (TFC) was determined as follows [20], the methanol extracts of pollen was retaken in $1 \mathrm{ml}$ of methanol and treated with $\mathrm{AlCl}_{3}$ methanol solution $(2 \%, 1 \mathrm{ml})$. 
After 30 min. the solution was mixed well and the intensity of color was measured at $\lambda=430$ $\mathrm{nm}$. rutin was used to calculate the standard curve $(0.1$ and $0.02 \mathrm{~g} / \mathrm{L})$ and the results were expressed as mg of rutin equivalents (REs) per g of extract. All the samples and the standards were analyzed in triplicate.

\subsection{Molybdate ion Reduction assay}

The total antioxidant capacity (TAC) of bee pollen extract was evaluated by the method of Prieto et al. [21]. An aliquot of $0.1 \mathrm{ml}$ of sample solution $(1 \mathrm{mg} / \mathrm{ml})$ was combined with $1 \mathrm{ml}$ of reagent solution (600 $\mathrm{mM}$ sulphuric acid, $28 \mathrm{mM}$ sodium phosphate and $4 \mathrm{mM}$ ammonium molybdate). The tubes were capped and incubated in a boiling water bath at $95^{\circ} \mathrm{C}$ for $90 \mathrm{~min}$. After the samples had cooled to room temperature, the absorbance of the aqueous solution of each was measured at $695 \mathrm{~nm}$ against a blank. A typical blank solution contained $1 \mathrm{ml}$ of reagent solution and the appropriate volume of the same solvent used for the sample and it was incubated under the same conditions. The antioxidant capacity was expressed as the number of equivalents of gallic acid (GAEs) ( $\mathrm{g} / \mathrm{g}$ of extract).

\section{RESULTS AND DISCUSSION}

\subsection{Extraction yield}

The results of extraction yield are shown in Figure 1. The differences in extraction yield and the concentrations were probably related to characteristics of the bee pollen, such as the harvesting season and regional flora.

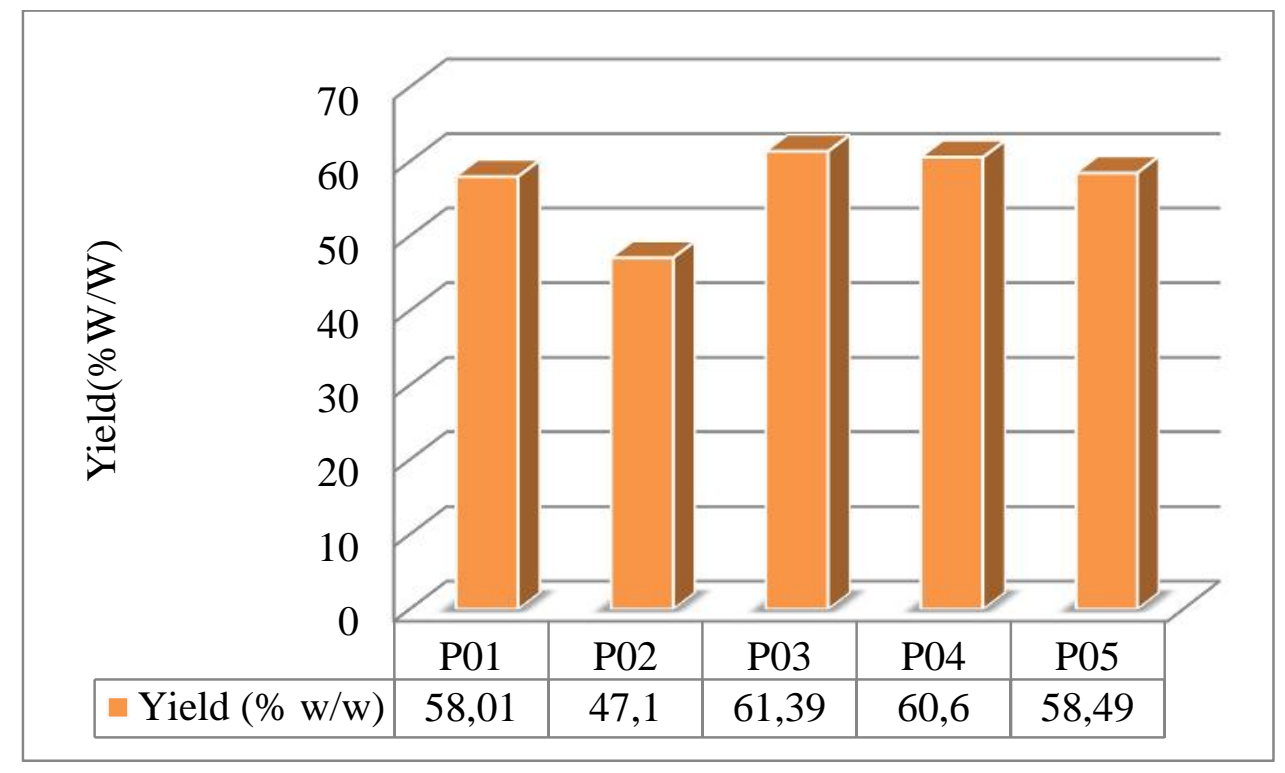

Fig.1. The variation of extraction yield for different types of bee pollen samples 


\subsection{Total Phenolic Content}

The results of the total phenolic content (TPC) for the five types of pollen are represented in Figure 2. This figure reveals that the phenolic content increases according to the floral source in the following order: Heteroflora < Eucalyptus < Rosemary < Wild Carrot.

The differences between other pollen samples could be attributed to the variations in composition (sugar, mineral and water content), to different locations in Algeria, and also to different floral sources of nectar.

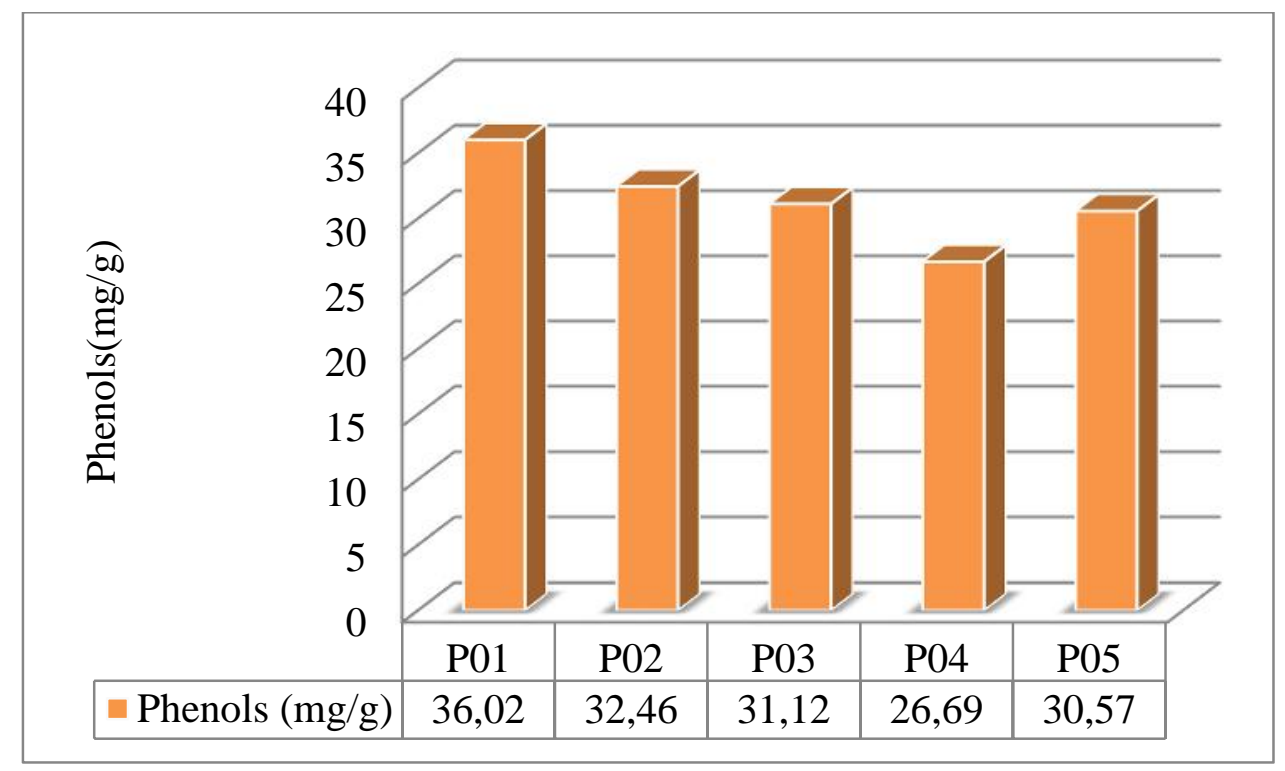

Fig.2. The variation of total phenolic content for different types of bee pollen samples

\section{TOTAL FLAVONOID CONTENT}

The bee pollen samples used in the present study showed a wide range of flavonoid amount. Details regarding the chemical composition are presented in Figure 3. 


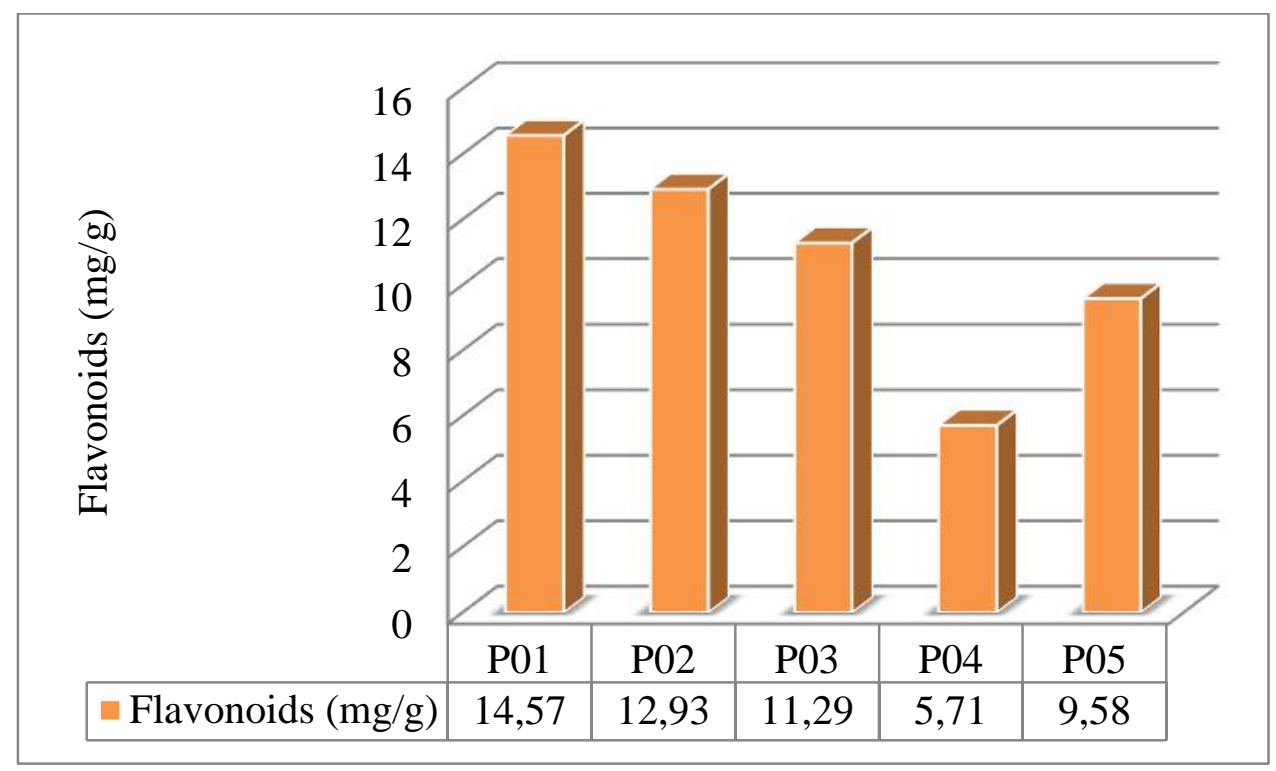

Fig.3. The variation of total flavonoid content for different types of bee pollen samples The results indicate that bee pollen contains significant amounts of flavonoids and phenolic compounds. Both these classes of compounds have good antioxidant potential and their effects on human nutrition and health are considerable.

\section{MOLYBDATE ION REDUCTION ASSAY}

There is a little information about total antioxidant activity of bee pollen by phosphomolybdate method. The method is utilized for the spectrofotometric quantitation of total antioxidant capacity and employs cost-effective reagents [21]. It based on the reduction of $\mathrm{Mo}(\mathrm{VI})$ to $\mathrm{Mo}(\mathrm{V})$ in presence of antioxidant compound and subsequent formation of a green phosphate/Mo(V) complex at acidic $\mathrm{pH}$ and at higher temperature.

Results obtained showed (Figure 4) that bee pollen possess antioxidant activity when compared to standard antioxidant compounds such as BHA, ascorbic acid, a natural antioxidant. 


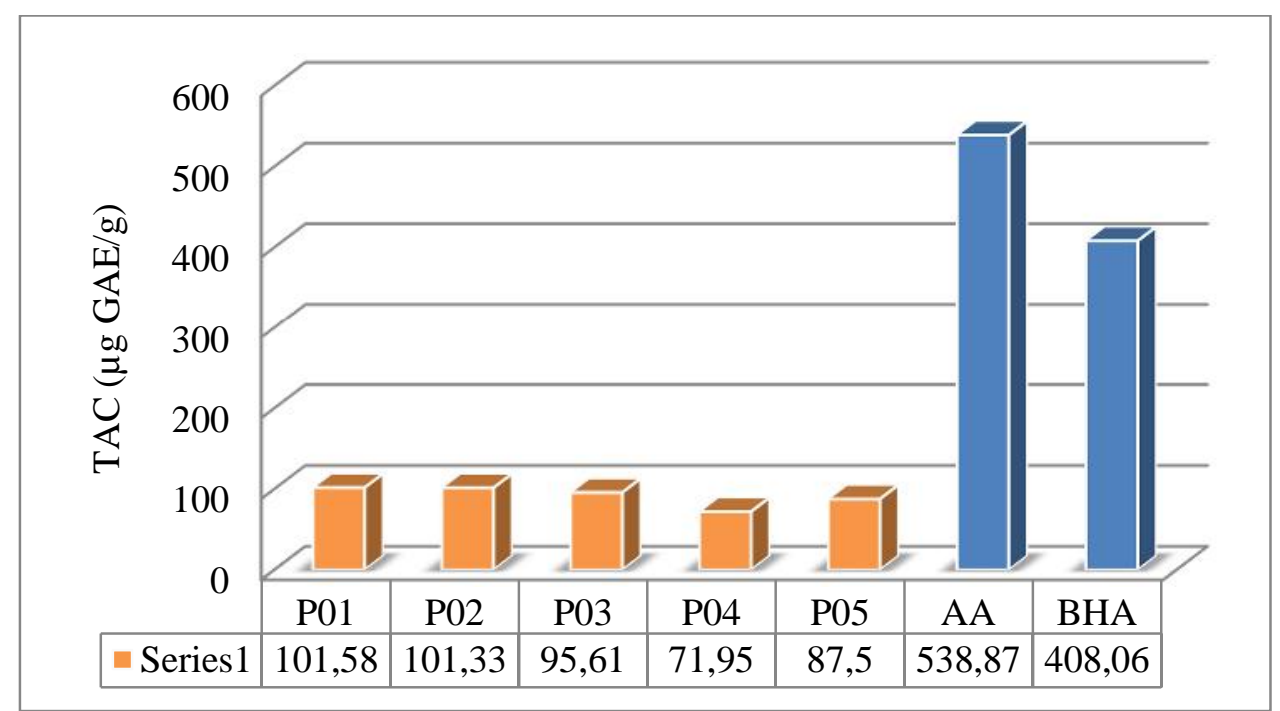

Fig.4. The variation of antioxidant activity for different types of bee pollen samples

The antioxidant activity for different types increased in the order: Heteroflora $<$ Eucalyptus < Rosemary $<$ Wild Carrot $<$ BHA $<$ Ascorbic acid.

The bee pollen of Boufarik showed high antioxidant activity (101, $58 \mu \mathrm{gGAE} / \mathrm{g}$ pollen) probably due to the high content of phenolic compounds present in pollen.

\section{CONCLUSIONS}

In the present study it is found that the methanolic extract of Algeria pollen contains substantial amount of phenolics and flavonoids and it is the extent of phenolics present in this extract being responsible for its marked antioxidant activity.

Results obtained showed that bee pollen possess antioxidant activity when compared to standard antioxidant compounds such as BHA, ascorbic acid, a natural antioxidant. Thus, it can be concluded that methanolic extract of bee pollen can be used as an accessible source of natural antioxidants with consequent health benefits.

\section{REFERENCES}

[1] Campos M.R.G., Bogdanov S., de Almeida-Muradian L.M.B., Szczesna T., Mancebo Y., Frigerio C., Ferreira F. J. Apicult. Res., 2008, 47, 156-163.

[2] Basim E., Basim H., Ozcan M. J. Food Eng. 2006, 77, 992-996.

[3] Ozcan M. J. Med. Food 2004, 7, 114-116. 
[4] Morais M., Moreira L., Feás X., Estevinho L.M. Food Chem. Toxicol. 2011, 49, 10961101.

[5] Bevzo V., Grygor'eva N.P. Ukr. Biokhim. Zh. 1997, 69, 115-117.

[6] Eraslan G., Kanbur M., Silici S. Food Chem. Toxicol. 2009, 47, 86-91.

[7] Pinto B., Cagiagli F., Riccio E., Reali D., Saric A., Balog T., Likic S., Scarpato R. Eur. J. Med. Chem. 2010, 45, 4122-4128.

[8] Furusawa E., Chou S.C., Hirazumi A., Melera A. Phytother. Res. 1995, 9, 255-259.

[9] Maruyama H., Sakamoto T., Araki Y., Hara H. Med. 2010, 10-30.

[10] Bogdanov S., A Review. Bee Product Science, 2011. Available online: http://www.beehexagon.net/files/file/fileE/Health/PollenBook2Review.pdf (accessed on 11 May 2012).

[11] Dorman H. J. D., Kosar M., Kahlos K., Holm Y., Hiltunen R. J. Agricult. Food Chemi., 2003, 51(16), 4563-4569.

[12] Almaraz-Abarca N., Campos M. G., Ávila-Reyes J.A., Jiménez N. N., Corral J.H., González-Valdez L. S. J.Food Comp.Anal. 2007, 20, 119-124.

[13] Javanmardi J., Stushnoff C., Locke E., Vivanco J. M. Food. Chem. 2003, 83(4), 547-550.

[14]. Rice-Evans C. A., Miller N. J., Paganga G. Bio.Med. 1996, 20(7), 933-956.

[15]. Campos M. G., Markham k. R.., Mitchell K. A.; Cunha A. P. Phytochemical Analysis. 1997, 8(4), 181-185.

[16]. Leja M., Mareczek A., Wyzgolik G., Klepacz-Baniak J., Czekonska K. Food Chem. 2007, 100(1), 237-240.

[17]. Kumazawa S., Hamasaka T., Nakayama T. Food Chem. 2004, 84(3), 329-339.

[18]. Meda A., Lamien C. E., Romito M., Millogo J., Nacoulma O. G. Food Chem. 2005, 91(3), 571-577.

[19]. Brand-Williams W., Cuvelier M. E., Berset C. LWT- Food Sc.Tech. 1995, 28, 25-30.

[20]. Chang C., Yang M.H., Wen H.M Andchern J.C. J. Food and Drug Anal. 2002, 3(10), 178-182.

[21]. Prieto P., Pineda M., Aguilar M. Spectrophotometric quantitation of antioxidant capacity through the formation of a phosphomolybdenum complex: specific application to the determination of Vitamin E, Anal. Biochem . 1999, 269, 337-341.

\section{How to cite this article}

Rebiai A and Lanez T. Chemical composition and antioxidant activity of APIS MELLIFERA bee pollen from northwest Algeria. J Fundam Appl Sci. 2012, 4(2), 155-163. 